\title{
Metallurgical Features of Steel Plates with Ultra Fine Grains in Surface Layers and their Formation Mechanism
}

\author{
Hidesato MABUCHI, Toshiei HASEGAWA ${ }^{1)}$ and Tadashi ISHIKAWA ${ }^{2)}$ \\ Oita R\&D Laboratories, Nippon Steel Corporation, Nishinosu, Oita City, 870-8566 Japan. \\ 1) Steel Research Laboratories, Nippon Steel Corporation, Shintomi, Futtsu City, 293-8511 Japan. \\ 2) Oita Works, Nippon Steel Corporation, Nishinosu, Oita City, 870-8566 Japan.
}

(Received on October 8, 1998; accepted in final form on January 20, 1999)

\begin{abstract}
Steel plates with heavy gauge, which are mainly applied to large steel structures, are consequently subject to improved low-temperature toughness as well as weldability by the application of general TMCPs. The advanced TMCP has been developed so as to industrially manufacture SUF (Surface layers with Ultra Fine grains) steel plates with high crack arrestability in avoiding unexpected catastrophic damage of large steel structures. The advanced TMCP is characterized by the accelerated cooling in the midst of rolling followed by controlled rolling in the reheating process, while the general TMCPs are described by the controlled rolling in air cooling followed by various types of accelerated cooling after the rolling. Mechanical properties governed by metallurgical features of surface layers are extremely improved by the adoption of SUF steel plates. In addition, the formation mechanism of ultra fine grains in the surface layers of SUF steel plates are discussed from metallographic viewpoints.
\end{abstract}

KEY WORDS: ultra fine grains; SUF steel plates; grain refining; grain coarsening; pinning effect; advanced TMCP; thermo-mechanical control process (TMCP); accelerated cooling; structural steel; weldability; low-temperature toughness; crack arrestability; fatigue strength.

\section{Introduction}

Structural steel plates with higher strength have been required to reduce the weight of large steel structures and their fabrication cost. In addition, requirements for higher toughness both in base plates and in their welded joints are getting more severe due to increased safety demand from global environmental standpoints. Then, it becomes more important to improve the weldability and low-temperature toughness of steel plates. Another requirement is made for excellent fracture toughness with crack arrestability so as to avoid catastrophic damage of large steel structures in accidental cases.

Among the above-mentioned requirements, the weldability including HAZ toughness with large heat input is considered to be one of the most difficult properties to achieve in high strength steels. Therefore, great efforts have been made for these fifteen years to improve the weldability not only by the adoption of the secondary refining process to decrease impurities and to apply Intra-Granular Ferrite (IGF) nucleated at fine inclusions, ${ }^{1,2)}$ such as $\mathrm{Ti}-\mathrm{B},{ }^{3)} \mathrm{Tin}-\mathrm{MnS}^{4)}$ and $\mathrm{Ti}_{2} \mathrm{O}_{3},{ }^{5)}$ but also by the cumulative progress of Thermo-Mechanical Control Process (TMCP) to reduce carbon equivalent and to render grain size finer. ${ }^{6-10}$ ) These general TMCPs include Thermo-Mechanical Rolling (TMR) without accelerated cooling, Accelerated Cooling (AC), Direct Quenching (DQ), Intercritical Quenching (L-treatment) and their combinations. It is strongly emphasized that all the general TMCPs except for TMR are described by the controlled rolling in air cooling, followed by various types of accelerated cooling after the entire completion of rolling. ${ }^{10)}$

Attempts to improve rolling productivity were done by the adoption of water cooling in the holding time of controlled rolling. ${ }^{11,12)}$ In the meantime, another effort to improve metallurgical properties was made through the internal hydrostatic stress increased by accelerated cooling in the midst of plate rolling. ${ }^{13)}$ Furthermore, the metallurgical finding on the formation of ultra fine grains was obtained by deforming ferritic phase right in heating process. $^{14)}$

On the other hand, the safety requirements are getting more strict for large steel structures at lowered service temperatures by the double integrity concept for emergency. It is well known that shear lips of plate surfaces associated with extensive plastic deformation can improve crack arrestability even against unstable running cracks. ${ }^{15)}$ Thus, SUF (Surface layers with Ultra Fine grains) steel plates were invented by the application of the aforesaid finding, ${ }^{14)}$ taking the enhanced formation of shear lips into consideration. ${ }^{10,16-21)}$ SUF steel plates, which are able to provide excellent fracture toughness, are industrially manufactured by developing the advanced TMCP, which is characterized by the accelerated cooling in the midst of rolling, followed by con- 


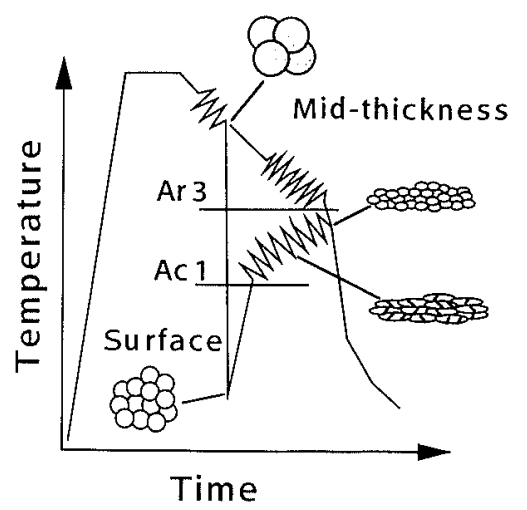

Fig. 1. Schematic manufacturing process of SUF steel plates by the advanced TMCP, along with the imaginative changes in grain size during the rolling.

trolled rolling in reheating process. ${ }^{10,22)}$

The present paper describes the metallurgical features of SUF steel plates and also discusses their formation mechanism.

\section{Experimental Procedure}

\subsection{Manufacturing Process of SUF Steel Plates}

SUF steel plates have essentially the same chemical composition as steel plates, which is ordinarily produced by AC of general TMCPs for hull structures, as listed in Table 1. SUF steel plates with gauges of $18 \mathrm{~mm}, 25 \mathrm{~mm}$ and $50 \mathrm{~mm}$ have been industrially manufactured by the advanced TMCP, which is the accelerated cooling in the midst of rolling followed by controlled rolling, as schematically depicted in Fig. $1,{ }^{10)}$ along with the imaginative changes in grain size during the rolling. It is then important to note in Fig. 1 that the controlled rolling in the surface layers of SUF steel plates is carried out during the reheating by the internal heat capacity of the plates themselves after the operation of the accelerated cooling.

\subsection{Testing Methods of Metallurgical Features in SUF Steel Plates}

First of all, in observing the metallographic features of SUF steel plates, the macrostructure and microstructures of SUF steel plates were revealed by $10 \%$ Nital and 5\% Nital, respectively.

The ferritic grain size is defined as the diameter of a circle with equivalent area. Then, the average grain size at each position of SUF steel plates was determined by the distribution of ferritic grain size observed by Scanning Electron Microscopy (SEM).

It has been confirmed that the results of mechanical tests fully satisfy the requirements for EH 355 grade in the standard of International Association of Classification Societies (IACS ) for hull structures. ${ }^{10,20,22)}$ Subsized Charpy V-Notch (CVN) impact tests were subsequently carried out in the positions of surface layers and of mid-thickness regions in demonstrating the drastic effects of SUF steel plates.

Regarding the crack arrestability of SUF steel plates, temperature-gradient-type ESSO tests (wide plate crack arresting tests) were carried out to clarify the temperature
Table 1. Chemical composition of SUF steel plates.

\begin{tabular}{|l|l|l|l|l|l|l|l|}
\hline Element & $\mathrm{C}$ & $\mathrm{Si}$ & $\mathrm{Mn}$ & $\mathrm{P}$ & $\mathrm{S}$ & Al & Ceq \\
\hline $\begin{array}{l}\text { M a s s } \\
(\%)\end{array}$ & 0.13 & 0.20 & 1.27 & 0.007 & 0.002 & 0.027 & 0.34 \\
\hline
\end{tabular}

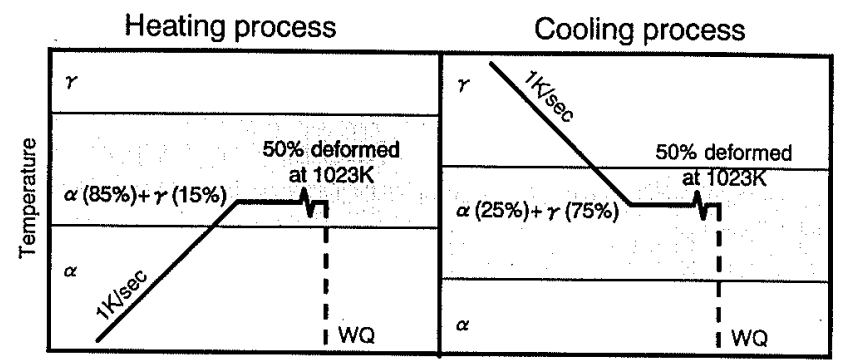

Fig. 2. Schematic thermal cycles to compare their influence on microstructures with $50 \%$ deformation in intercritical regions.

dependence of crack arresting fracture toughness, $\mathrm{Kca}$, of SUF steel plates. In addition, duplex-type ESSO tests (large scaled crack arresting tests of duplex type) with a width of $1200 \mathrm{~mm}$ were demonstrated in order to confirm the crack arrestability of SUF steel plates against an unstable running crack at $203 \mathrm{~K}$ under an applied stress of $360 \mathrm{~N} / \mathrm{mm}^{2}$. The testing methods of these two types of ESSO tests were minutely explained in previous reports. ${ }^{10,20,22)}$

Fatigue tests using smooth flat specimens of $6 \mathrm{~mm}$ taken from surface layers and mid-thickness regions of SUF steel plates were carried out to evaluate the fatigue strength both in air and in artificial sea water. The methods of fatigue tests were described elsewhere in detail. $^{23)}$

\subsection{Testing Methods to Elucidate Formation Mecha- nism of Ultra Fine Grains in SUF Steel Plates}

Cylindrical samples with a diameter of $8 \mathrm{~mm}$ and a length of $12 \mathrm{~mm}$ were taken from ordinarily-rolled steel plates, which have the same chemical composition as SUF steel plates, as listed in Table 1.

First of all, samples were $50 \%$ deformed by a single pass at $1023 \mathrm{~K}$, employing the simulator of hot deformation both in heating process and in cooling process as schematically shown in Fig. 2, and were then cooled rapidly to confirm the influence of thermal cycles on ferritic grain size and to study their microstructures by SEM and Transmission Electron Microscopy (TEM). ${ }^{14)}$

Samples were cooled to various temperatures and reheated to $1023 \mathrm{~K}$, simulating thermal cycles in surface layers of SUF steel plates as shown in Fig. 3(a), and were then cooled rapidly to study the influence of cooling temperature on austenitic fraction after being reheated at $1023 \mathrm{~K}$, compared with that before the reheating. ${ }^{18)}$ Other samples were $50 \%$ deformed by a single pass at $1023 \mathrm{~K}$ as shown in Fig. 3(b), and were then cooled rapidly to investigate the influence of cooling temperature on ferritic grain size. ${ }^{18)}$

Samples were cooled to $673 \mathrm{~K}$ and reheated to various 


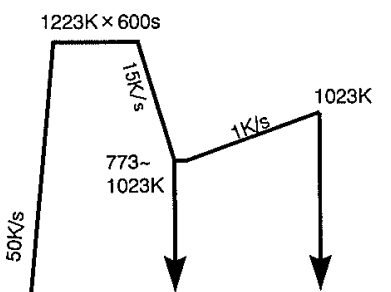

(a) without deformation

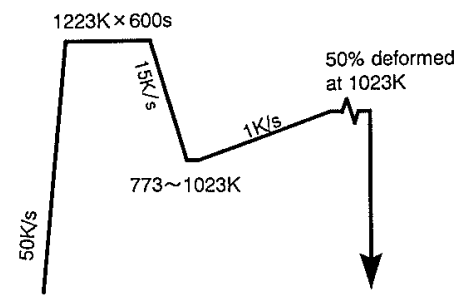

(b) with $50 \%$ deformation

Fig. 3. Simulated thermal cycles in surface layers of SUF steel plates to study the influence of cooling temperature on austenitic fraction and ferritic grain size.

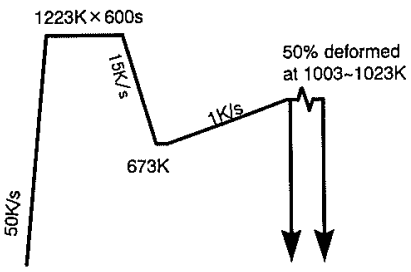

(a) without or with deformation

(b) with multi-pass deformation

Fig. 4. Simulated thermal cycles in surface layers of SUF steel plates to study the influence of reheating temperature and deformation conditions on austenitic fraction.

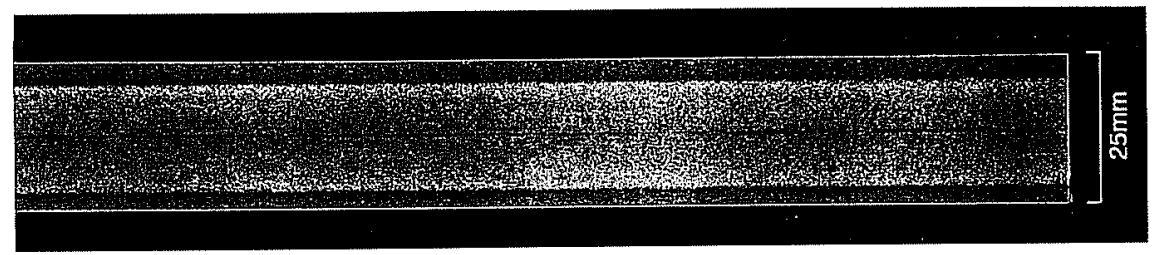

(a) Macrostructure

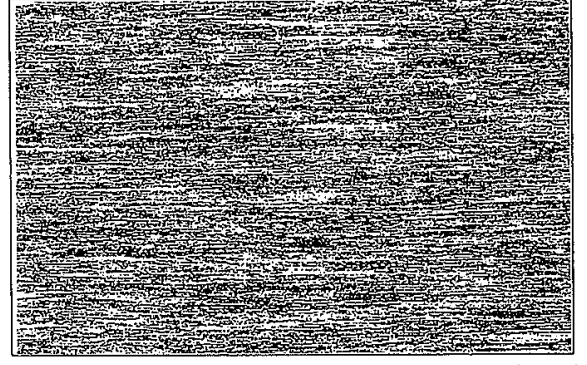

(b) Microstructure in surface layer

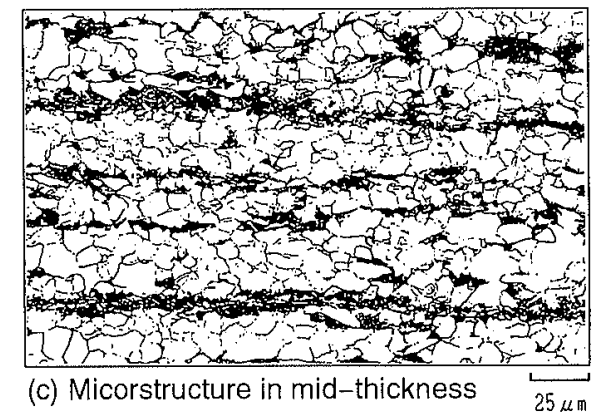

Fig. 5. Macrostructure of the whole section and microstructures in a surface layer and the mid-thickness of a SUF steel plate of $25 \mathrm{~mm}$.

temperatures as in Fig. 4, and other samples were $50 \%$ deformed by multiple passes in reheating process and by a single pass after being reheated, and then cooled rapidly to study the influence of deformation conditions on austenitic fraction.

In addition, Analytical Electron Microscope (AEM) analyses for ultra fine grains of SUF steel plates were carried out to investigate finely dispersed precipitates, which were identified by Energy Dispersive Spectrometry (EDS), as a potential candidate to suppress ferritic grain coarsening by pinning. ${ }^{10)}$

\section{Experimental Results}

\subsection{General Properties of SUF Steel Plates}

Figure 5 reveals the macrostructure of a SUF steel plate compared with its microstructures. Dark colour regions correspond to the layers of ultra fine grains in the SUF steel plate.

The grain size in the surface layer is too fine to distinguish even by magnified micrograph, as also shown in Fig. 5. It is then noted that neither pearlite nor coarse cementite is observed in the surface layers.

Figure 6 shows the cross-sectional distribution of the av erage ferritic grain size in a SUF steel plate. The average grain size in the surface layer is constantly smaller than $2 \mu \mathrm{m}$, while that in the mid-thickness is somewhat

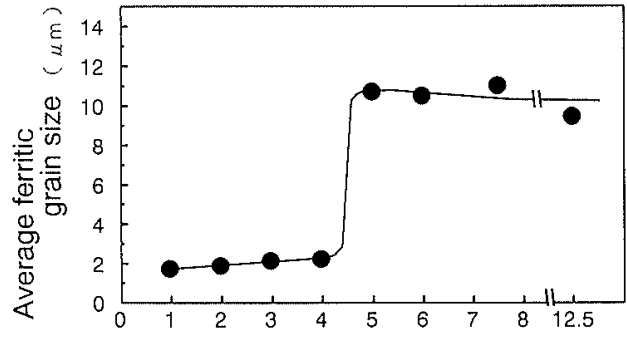

Distance from surface of plate $(\mathrm{mm})$

Fig. 6. Cross-sectional distribution of the average ferritic grain size in a SUF steel plate of $25 \mathrm{~mm}$.

smaller than that of steel plates manufactured by AC of general TMCPs. It is also emphasized that the average grain size changes steeply at the position of one sixth of the plate with a thickness of $25 \mathrm{~mm}$.

Mechanical properties of SUF steel plates satisfy the requirements for EH355 grade of IACS standard, as listed in Table 2. Figure 7 shows the results of sub-sized CVN impact tests. The surface layers of SUF steel plates are too tough to determine Ductile-Brittle Transition Temperature (DBTT) at the temperature of liquid nitrogen $(77 \mathrm{~K})$, demonstrating the drastic effect of SUF steel plates. Furthermore, the fracture appearance of CVN specimens in the surface layers is observed fully ductile even at $77 \mathrm{~K}$ due to the presence of many micro- 
Table 2. Mechanical properties of SUF steel plates.

\begin{tabular}{|c|c|c|c|c|}
\hline Thickness & YP & TS & El. & CVN at 233K \\
\hline $18 \mathrm{~mm}$ & $451 \mathrm{MPa}$ & $503 \mathrm{MPa}$ & $18 \%$ & $202 \mathrm{~J}$ \\
\hline $25 \mathrm{~mm}$ & $431 \mathrm{MPa}$ & $526 \mathrm{MPa}$ & $23 \%$ & $215 \mathrm{~J}$ \\
\hline $50 \mathrm{~mm}$ & $436 \mathrm{MPa}$ & $536 \mathrm{MPa}$ & $33 \%$ & $221 \mathrm{~J}$ \\
\hline
\end{tabular}

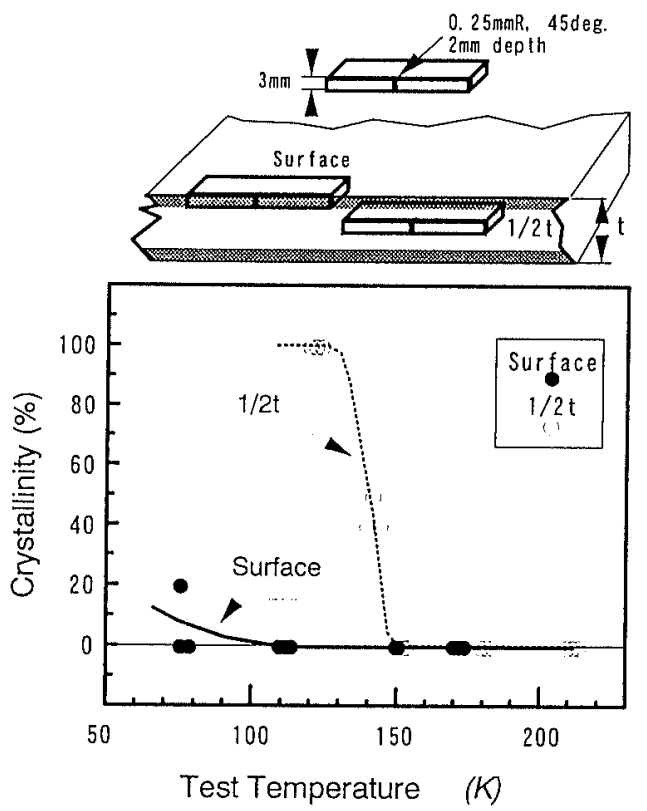

Fig. 7. Sub-sized CVN impact test results in a surface layer and the mid-thickness region of a SUF steel plate of $25 \mathrm{~mm}$.

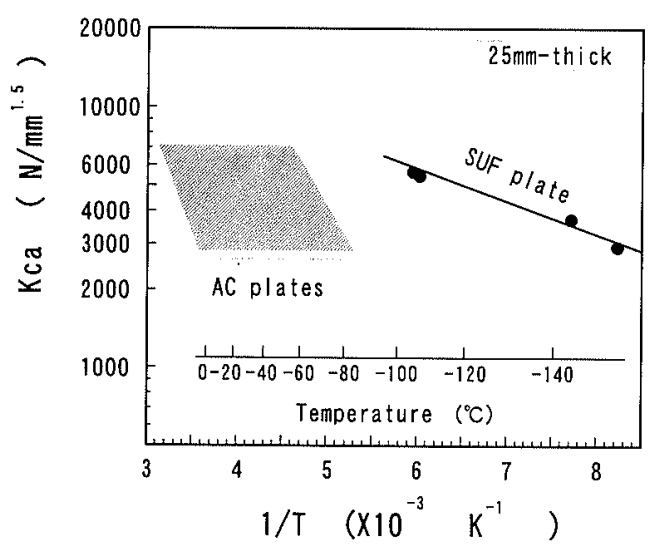

Fig. 8. Temperature-gradient-type ESSO test results of SUF steel plates of $25 \mathrm{~mm}$, compared with those of AC steel plates of $25 \mathrm{~mm}$.

separations through the textures developed by strict controlled rolling. On the other hand, the DBTT in the mid-thickness of SUF steel plates is as low as $133 \mathrm{~K}$.

Thus, the terminology of SUF has been named after these metallographic features of Surface layers with Ultra Fine grains, as especially shown in Figs. 5 and 6.

\subsection{Special Features of SUF Steel Plates}

Figure 8 shows the results of the temperature-gradienttype ESSO tests, comparing the Kca values of SUF steel plates of $25 \mathrm{~mm}$ with those of steel plates manufactured

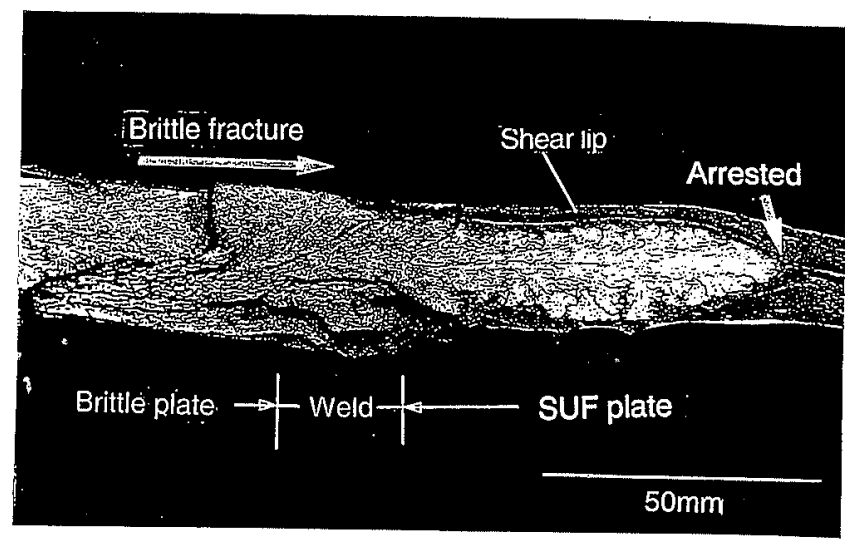

Fig. 9. Fracture appearance of arrested crack by the SUF steel plate of $25 \mathrm{~mm}$ in duplex-type ESSO tests at $203 \mathrm{~K}$ under $360 \mathrm{~N} / \mathrm{mm}^{2}$.

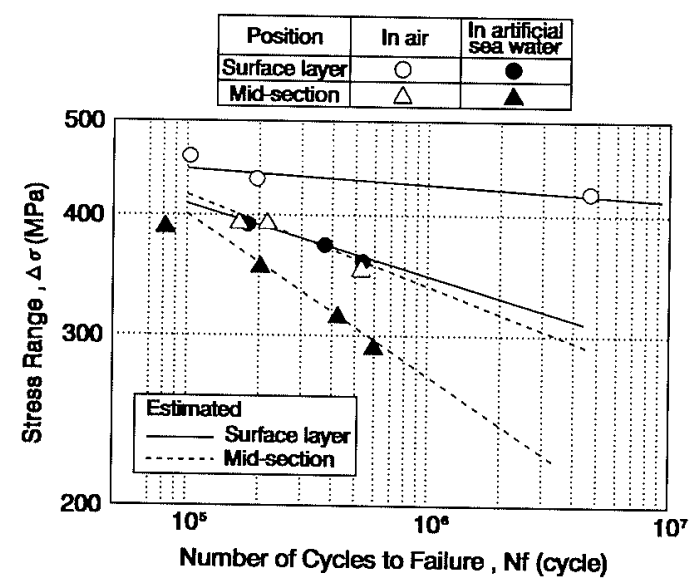

Fig. 10. Fatigue test results of SUF steel plates with smooth flat specimens both in air and in artificial sea water.

by AC of general TMCPs. The Kca values of SUF steel plates are much higher than those of AC steel plates. It is also shown in Fig. 8 that the temperature to obtain the Kca value of $6000 \mathrm{~N} / \mathrm{mm}^{1.5}$ for SUF steel plates is as low as $173 \mathrm{~K}$, which is low enough to arrest unstable running cracks and is better than that for $2.5 \% \mathrm{Ni}$ steel plates. $^{24-26)}$

Figure 9 exhibits the fracture appearance of the arrested crack by the SUF steel plate of $25 \mathrm{~mm}$ against an unstable running crack in the $\mathrm{AC}$ plate as the brittle plate in the duplex-type ESSO tests. The enhanced formation of shear lips in both surfaces of the SUF steel plate are observed with extensive plastic deformation, resulting in the excellent performance of crack arrestability even at $203 \mathrm{~K}$.

Figure 10 shows the fatigue test results of SUF steel plates both in air and in artificial sea water, comparing the properties of the surface layers with those of the mid-thickness. ${ }^{23)}$ It is evidently pointed out that fatigue properties of the surface layers are much higher than those of the mid-thickness both in air and in artificial sea water. It should be also noted that the fatigue strength of surface layers in artificial sea water is as high as that of mid-thickness in air.

Figure 11 depicts the behavior of crack propagation in the surface layers of SUF steel plates by fatigue tests in air. Many crack branches are observed due to the 
presence of micro-separations introduced by developed textures, resulting in the effective delay of crack propagation.

It is hereby summarized that whatever property is governed by metallurgical features of surface layers such as crack arrestability and fatigue strength can be extremely improved by the adoption of SUF steel plates.

\section{Discussions}

\subsection{Previous Studies on Grain Refinement}

The definition of general TMCPs and their progress have been reviewed in detail in previous reports, ${ }^{9,10)}$ with their schematic depiction as shown in Fig. 12 for practical steels. It is consequently understood that all the general TMCPs are described by the controlled rolling in air cooling, being followed by various types of accelerated cooling after the entire completion of rolling.

It is well known that refining methods of microstructures in the general TMCPs consist of three basic processes. $^{6,9)}$ First, the low temperature reheating of slabs is primarily carried out to suppress austenitic grain coarsening. Second, controlled rolling is employed to recrystallize austenitic grains and to introduce deformation bands in elongated austenite with the assistance of micro-alloying. Finally, accelerated cooling is applied to

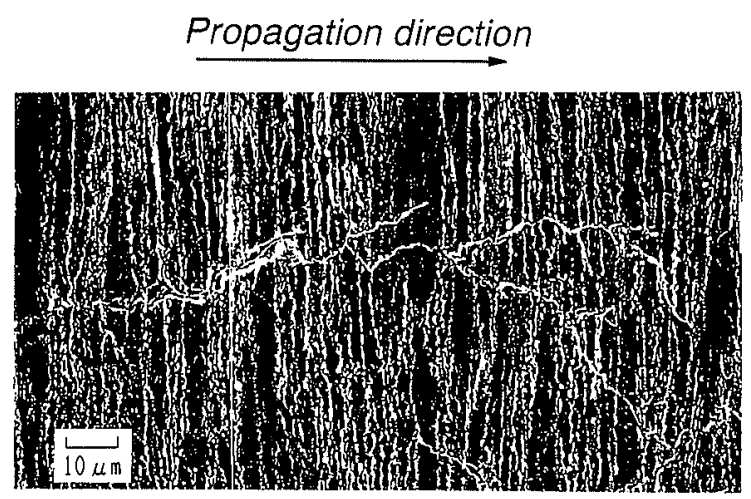

Fig. 11. Propagation behavior of fatigue cracks observed in air with many crack branches in surface layers of SUF steel plates. increase the driving force for $\gamma-\alpha$ transformation and the nucleation density of ferrite in undercooled austenite. However, the ferritic grain size of $5 \mu \mathrm{m}$ is the lower limit obtainable by the application of present production process.

On the other hand, the formation of finer grain ferrite was experimentally investigated by repeating the $\gamma-\alpha$ transformation of a low alloy steel. ${ }^{27)}$ The results showed the polygonal ferrite of around $3 \mu \mathrm{m}$ with small amounts of second phases, although the DBTT of the steel was not improved so much as their grain size due to the presence of the second phases. Then, repeating $\gamma-\alpha$ transformation seems inapplicable to practical low alloy steels to obtain fine ferrite.

The formation of ultra fine ferrite in a mild steel was recently studied by multi-pass warm deformation of quenched martensitic microstructure with deformation direction changed, being followed by annealing in laboratory. ${ }^{28)}$ As a result, the ultra fine ferrite was obtained down to $1 \mu \mathrm{m}$ with the grain boundary angle of over $15^{\circ}$. However, it is considered to be difficult to obtain industrially martensitic microstructures by quenching mild steels with large scale size.

\subsection{Formation Mechanism of Ultra Fine Grains}

Regarding factors on further refining ferritic grains, other approaches have been considered from three metallurgical viewpoints. One is to employ ferritic grain refining by recrystallization due to the warm deformation of ferrite in heating process. ${ }^{14)}$ Another is to obtain the fine precipitates of ferrite or cementite by reheating supercooled austenite ${ }^{18)}$ or by reheating ferrite supersaturated with carbon, ${ }^{10}$ ) respectively on the basis of the same principle as the formation of fine precipitates such as AlN in steels ${ }^{29-31)}$ or Guinier-Preston Zones in Aluminum. ${ }^{32)}$ The third is to suppress the grain coarsening not of austenite but of ferrite by pinning with finely dispersed cementite. ${ }^{10}$

\subsubsection{Influence of Thermal Cycles on Ferritic Grain Size}

Figure 13 shows the influence of hot deformation both in heating process and in cooling process on ferritic grain

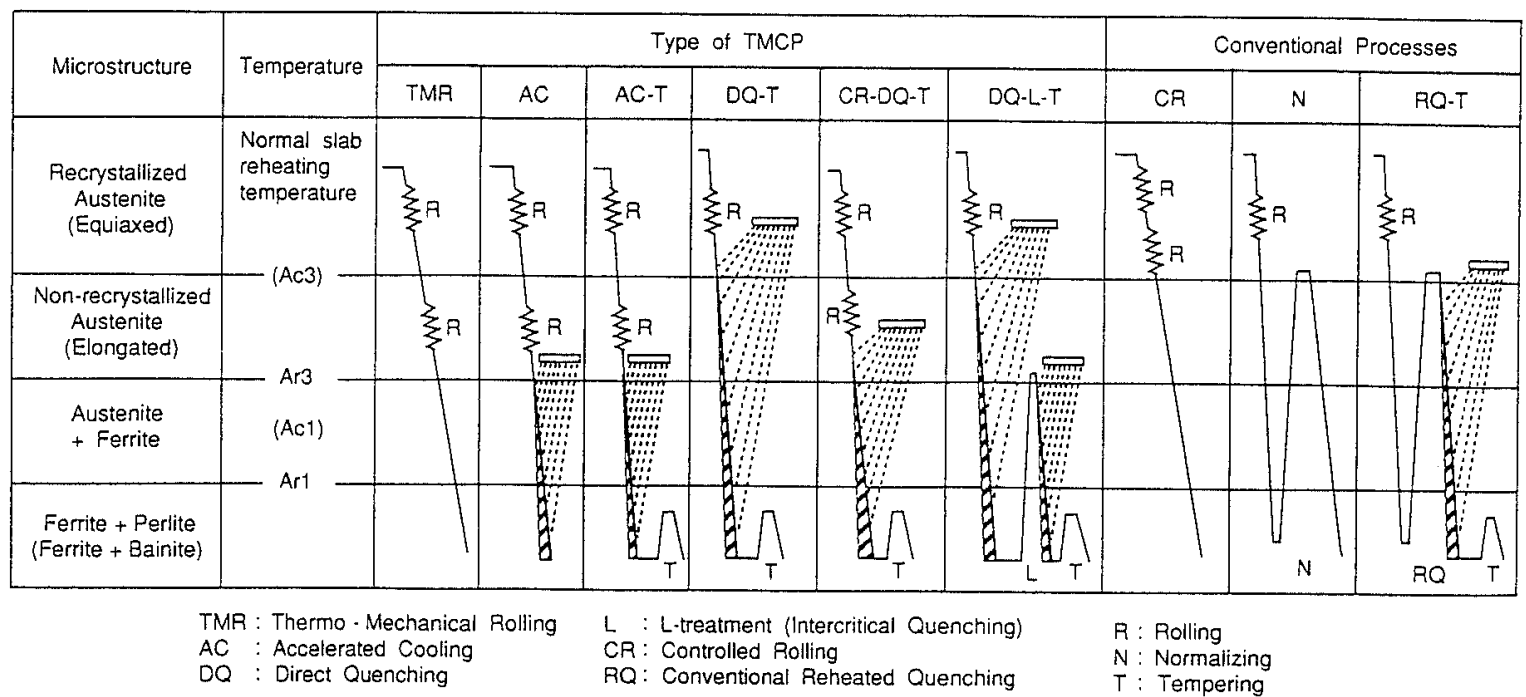

Fig. 12. Schematic diagrams of general TMCPs, compared with conventional process. 


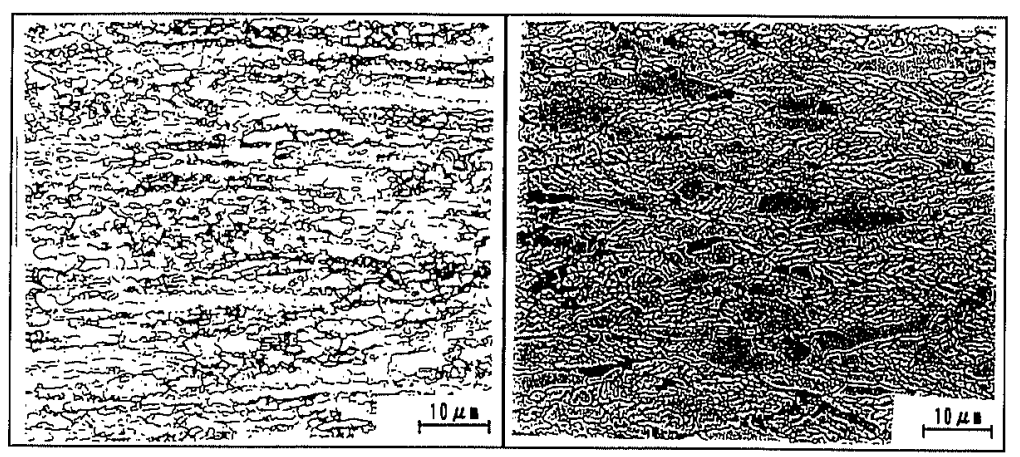

(a)In heating process

(b)In cooling process

Fig. 13. Influence of hot deformation on ferritic grain size in heating process, compared with that in cooling process.

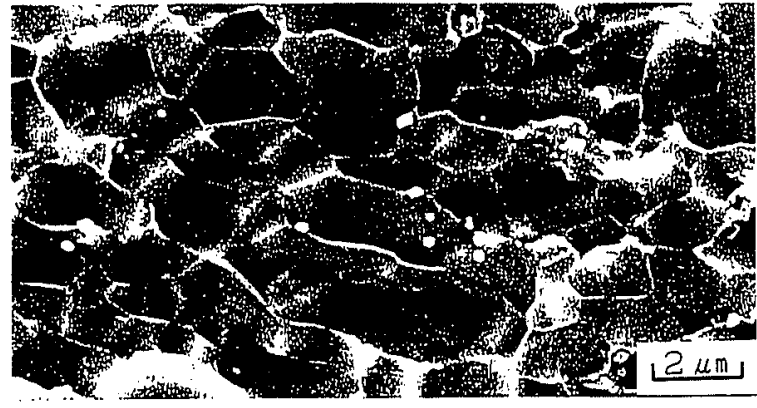

(a) SEM micrograph.

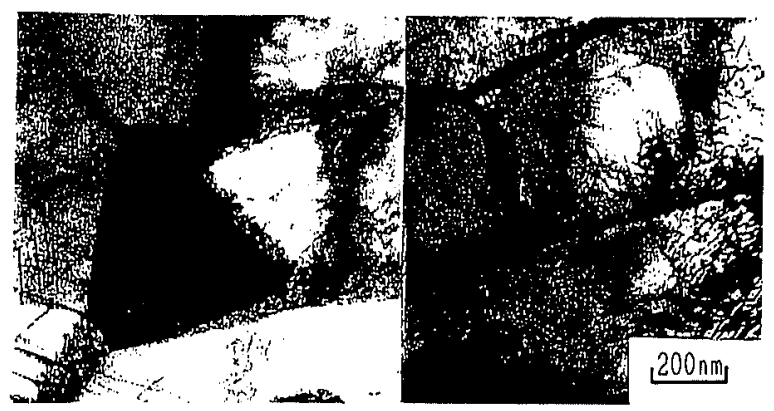

(b) TEM micrograph.

Fig. 14. Magnified microstructures of ultra fine grains deformed in heating process, observed by SEM and TEM.

size. ${ }^{14)}$ Ferritic grains deformed in heating process become extremely finer than that in cooling process. It is also noted in Fig. 13 that the trace of elongated austenite are obviously observed by deformed microstructures in the intercritical region of cooling process.

These results are considered as follows: Large difference in ferritic grain size is essentially caused by the difference in ferritic fraction, $85 \%$ and $25 \%$ when deformed in heating process and in cooling process, respectively. Then, ferrite in the former case may tend to be significantly recovered and recrystallized by high dislocation density due to hot deformation in ferritic phase. On the other hand, ferrite in the latter case is considered to be the same one as produced by the intercritical rolling of conventional TMR.

Figure 14 reveals magnified microstructures of ultra fine grains obtained by deforming in heating process. ${ }^{14)}$

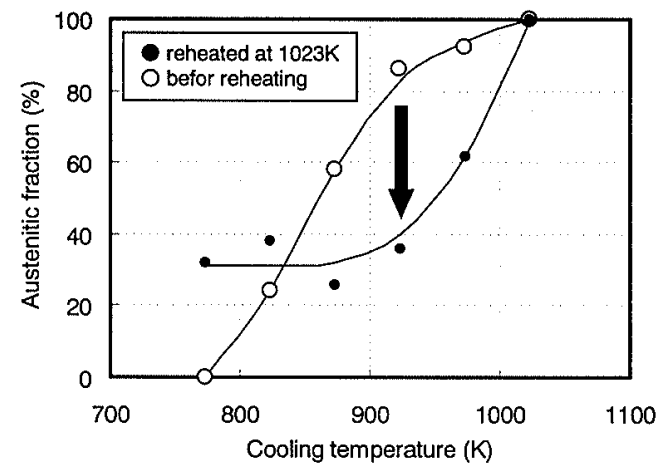

Fig. 15. Infiuence of cooling temperature on austenitic fraction before heating and after reheated to $1023 \mathrm{~K}$ without hot deformation.

The SEM micrograph exhibits homogeneous ferritic grains with the average size of $2 \mu \mathrm{m}$ or less. The TEM micrograph also indicates that ferrite deformed in heating process is well recovered and recrystallized, showing low dislocation density for the warm deformation.

It is also noted in Fig. 14 that globular precipitates of cementite, which are as fine as $0.2 \mu \mathrm{m}$, are observed in the vicinity of ferritic grain boundaries. It is then supposed that finely dispersed cementite may precipitate from ferrite supersaturated with carbon in heating process and be subsequently spheroidized at higher temperatures, implying the influence of cementite on the pinning of ferritic grain coarsening. ${ }^{10}$ )

Thus, the above-mentioned mechanism is considered to govern the formation of ultra fine grains in the regions from the outer side to the mid-side of SUF portion, where the ferritic phase can be predominant by accelerated cooling and be consequently deformed by the subsequent rolling in heating process, as also discussed in Fig. 16.

\subsubsection{Influence of Cooling Temperature on Austenitic Fraction and Ferritic Grain Size}

Figure 15 shows the influence of cooling temperature on austenitic fraction after being reheated to $1023 \mathrm{~K}$ without any deformation compared with that before the reheating, being rearranged from the previous report. ${ }^{18)}$ Austenitic fraction before the reheating decreases monotonously down to $0 \%$ as cooling temperature is lowered to $773 \mathrm{~K}$, while that after being reheated to $1023 \mathrm{~K}$ first decreases rapidly but stays at the 


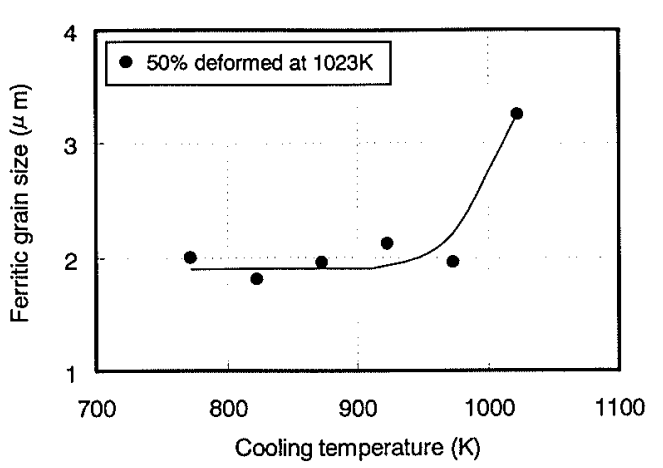

Fig. 16. Influence of cooling temperature on ferritic grain size with $50 \%$ deformation after reheated to $1023 \mathrm{~K}$.

constant fraction of $30 \%$ at temperatures equal to or lower than $923 \mathrm{~K}$. The incremental ferritic fraction seems to result from the driving force of $\gamma-\alpha$ transformation enhanced by reheating supercooled austenite, as stated before.

Figure 16 shows the influence of cooling temperature on ferritic grain size with $50 \%$ deformation after being reheated to $1023 \mathrm{~K} .{ }^{18)}$ Ferritic grain size is first getting finer and stays at the average size of $2 \mu \mathrm{m}$ or less as the cooling temperature becomes $973 \mathrm{~K}$ or lower. The trend line in Fig. 16 seems to be closely related to that for solid marks in Fig. 15, but an inconsistency is found between the two lines around $973 \mathrm{~K}$.

It is consequently considered that the formation of ultra fine grains is caused by the deformation of ferrite pre-existing at $1023 \mathrm{~K}$ and also by the additional precipitation of fine ferrite through the reheating of supercooled austenite with the assistance of the straininduced transformation. The present mechanism is then expected to govern the formation of ultra fine grains in the inner side of SUF portion, where the ferritic phase can not be always predominant even after the accelerated cooling.

\subsubsection{Influence of Reheating Temperature and De-} formation Conditions on Austenitic Fraction

Figure 17 clarifies the influence of reheating temperature after cooled to $673 \mathrm{~K}$ on austenitic fraction, comparing the influence of various deformation conditions. ${ }^{33)}$ Austenitic fraction seems to increase linearly as a function of reheating temperature whether deformation is applied or not by a single pass. Then, the influence of single pass deformation after the reheating on austenitic fraction seems much smaller than that of reheating temperature.

It is also important to point out in Fig. 17 that austenitic fraction is significantly decreased to nearly zero by multi-pass deformation in the reheating process of undercooled austenite at higher reheating temperatures. ${ }^{33)}$ This phenomenon can be explained by increased nucleation sites on deformation bands or by the straininduced transformation.

Hence, the above phenomenon is speculated to govern the formation of ultra fine grains in the most inner side of SUF portion, where the driving force for $\gamma-\alpha$ transformation might be insufficient, since the undercooled temperature in the most inner side can be less than that

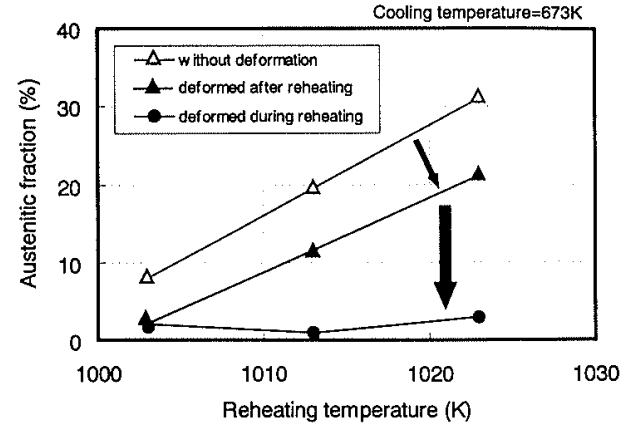

Fig. 17. Influence of reheating temperature with various deformation conditions on austenitic fraction after cooled to $673 \mathrm{~K}$.

in the mid-side and the outer side.

\subsubsection{Influence of Fine Precipitates of Cementite on the Suppression of Ferritic Grain Coarsening}

Figure 18 shows the evidence of fine precipitates of cementite by the application of AEM. ${ }^{10)}$ Finely dispersed precipitates of cementite, which have been identified by the EDS spectrum of AEM, are observed to exist along ferritic grain boundaries and their sub-grain boundaries. Then, the above cementite dispersed in appropriate sites can play the definite role rather than the potential candidate to suppress the ferritic grain coarsening by pinning, just as predicted in Secs. 2.3., 4.2. and 4.2.1.

It is also pointed out in Fig. 18 that two types of cementite are obviously observed along ferritic grain boundaries and their sub-grain boundaries. One is globular cementite, which may precipitate from ferrite supersaturated with carbon in reheating process and be subsequently spheroidized at higher temperatures.

Another is plate-like cementite, which is aligned along ferritic grain boundaries and their sub-grain boundaries. The above cementite might be resulted from the straininduced precipitation or from the rapid change in $\mathrm{C}$ solubility due to the progressive formation of fine ferritic grains, which can be obtained by reheating supercooled austenite or by rolling undercooled austenite, just as mentioned in Secs. 4.2.2 and 4.2.3., respectively.

It is consequently anticipated that cementite, which is finely dispersed along ferritic grain boundaries and their sub-grain boundaries, has to be inevitable to suppress the coarsening of ultra fine grains in the SUF portion by pinning.

\subsubsection{Short Summary}

The ultra fine grains can be formed through three functional mechanisms in SUF steel plates as follows:

One is the deformation of ferritic phase in heating process, which can increase ferritic fraction by the raise of $\mathrm{A}_{\mathrm{c} 3}$. Ferrite deformed at higher temperatures tends to be recovered and recrystallized by highly accumulated dislocations.

Another is reheating supercooled austenite. Supercooled austenite in reheating process can increase ferritic fraction and form fine precipitates of ferrite, according to the same principle as the precipitation of the second phase in supersaturated solid solution by tempering.

The third is the progressive deformation of under- 

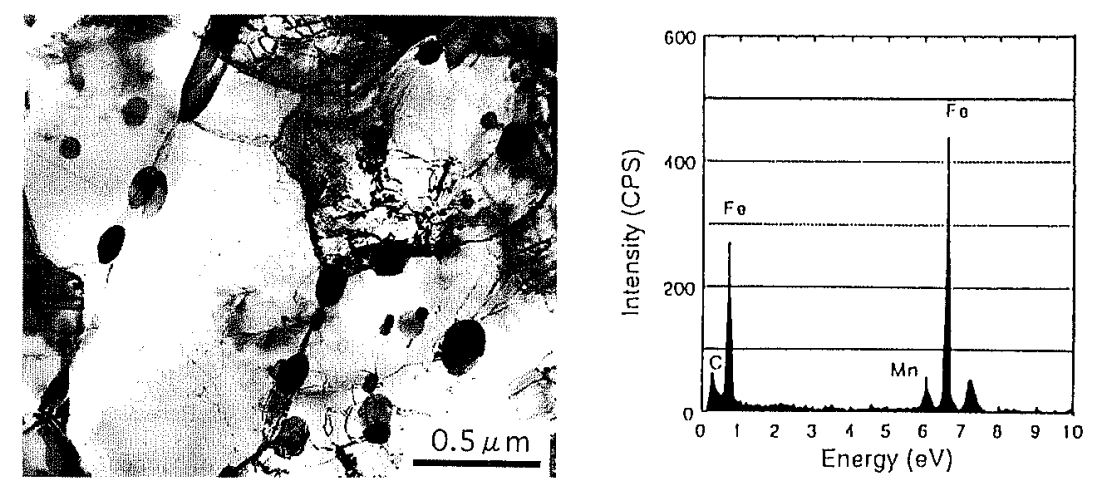

(a) Globular cementite
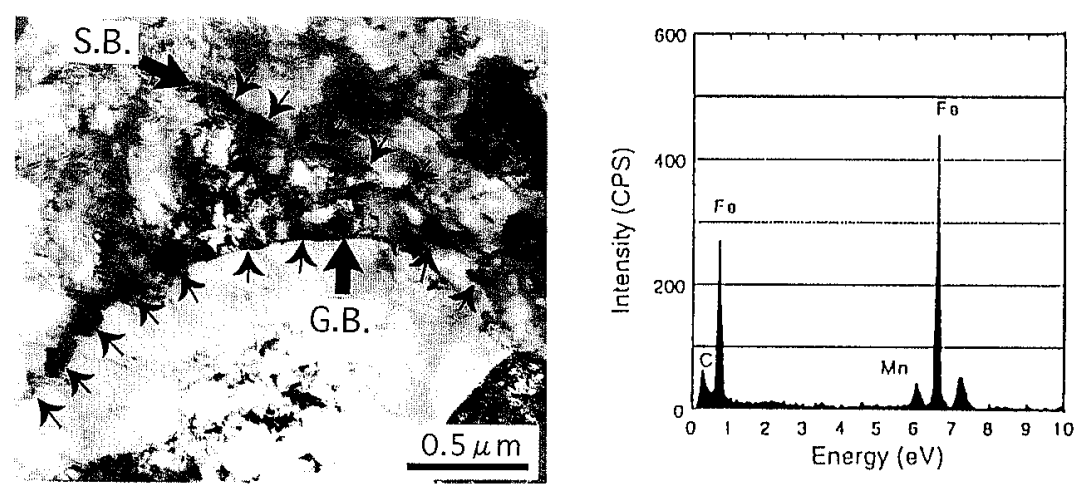

(b)Plate-like cementite

Fig. 18. AEM images of fine precipitates of cementite dispersed along ferritic grain boundaries and their sub-grain boundaries with their EDS spectrum in surface layers of SUF steel plates.

cooled austenite in reheating process. Ultra fine grains of ferrite are produced at increased nucleation sites on deformation bands or by strain-induced transformation.

In addition, finely dispersed precipitates of cementite, which exist along ferritic grain boundaries and their sub-grain boundaries with two types of morphology, have play the definite role to suppress the coarsening of ultra fine grains in SUF steels by pinning.

The present mechanisms to form ultra fine grains and to suppress their coarsening are strongly supported by the former connotations, as stated in Secs. 4.2 and 4.2.1.

\subsection{Reason for Improving Fatigue Properties}

In the present studies, it has been obviously demonstrated by the application of SUF steel plates that fatigue strength of the surface layers is much higher than that of the mid-thickness both in air and artificial sea water. It is also confirmed that fatigue strength of surface layers in artificial sea water is as high as that of mid-thickness in air, which is considered equal to general properties of $\mathrm{AC}$ steel plates.

Reasons to improve fatigue properties of SUF steel plates are considered as follows: one is to suppress the initiation of fatigue crack, the other is to delay the propagation of fatigue crack. The suppression of crack initiation may be brought about by the absence of coarse cementite or presumably sulfide and by the reduction of grain boundary segregation of impurities ${ }^{34)}$ due to ultra fine grains in surface layers, from the viewpoints of initial crack length or of the potential difference in local cell. The delay of crack propagation may be led to not only by ultra fine grains in surface layers but also by many crack branches due to developed textures.

It is shortly summarized that whatever property is governed by metallurgical features of surface layers of steel plates such as fatigue strength, crack arrestability and low-temperature toughness can be improved by the adoption of SUF steel plates.

\section{Conclusion}

SUF steel plates with ultra fine grains in surface layers have been invented by the development of the advanced TMCP. The advanced TMCP is characterized by the accelerated cooling in the midst of rolling followed by controlled rolling during the reheating by the internal heat capacity of plates themselves, while the general TMCPs are described by the controlled rolling in air cooling followed by various types of accelerated cooling after the entire completion of rolling.

It is also confirmed that whatever property is governed by metallurgical features of surface layers of steel plates 
is able to be improved drastically by the adoption of SUF steel plates. Eventually, SUF steel plates have outstanding performance as following:

- Surface layers of SUF steel plates consist of ultra fine grains, of which average size is smaller than $2 \mu \mathrm{m}$, and of finely dispersed precipitates of cementite, which are as fine as $0.2 \mu \mathrm{m}$, along ferritic grain boundaries and their sub-grain boundaries.

- SUF steel plates have excellent mechanical properties such as low-temperature toughness, crack arrestability and fatigue strength, due to metallurgical features of their surface layers.

- SUF steel plates have enough weldability as the grade of EH355 in the standard of IACS by the adoption of the same chemical composition as AC steel plates of general TMCPs.

Further investigation has been carried out in elucidating the formation mechanism of ultra fine grains in surface layers of SUF steel plates from metallographic viewpoints. The ultra fine grains of SUF steel plates can be formed through three functional mechanisms and their pinning effect as follows:

- One is the ferritic grain refining by their recovering and recrystallizing due to highly accumulated dislocations through hot deformation and increased ferritic fraction in the heating process of the ferritic phase.

- Another is the ferritic precipitation by reheating supercooled austenite due to the sufficient driving force for $\gamma-\alpha$ transformation.

- The third might be the influence of strain-induced transformation or increased nucleation sites on deformation bands due to the progressive deformation of undercooled austenite in reheating process.

- The ultra fine grains of ferrite formed through the above-mentioned mechanism have to be suppressed by fine precipitates of cementite dispersed along ferritic grain boundaries and their sub-grain boundaries.

\section{Acknowledgements}

The authors gratefully acknowledge Dr. Atsuhiko YOSHIE and Mr. Yuji NOMIYAMA for their coworking on fundamental research and production tests to develop SUF steel plates, respectively.

\section{REFERENCES}

1) Use of Fine Inclusions in Microstructural Control of Steels, ed. by Society on Basic Research, ISIJ, Tokyo, (1995).

2) H. Mabuchi and S. Aihara: Bull. Jpn. Inst. Met., 34 (1995), 301.

3) Y. Ohno, Y. Okamura, S. Matsuda, K. Yamamoto and T. Mukai: Tetsu-to-Hagané, 73 (1987), 1010.

4) Y. Tomita and N. Saito: ISIJ Int., 34 (1994), 829.

5) H. Homma, S. Ohkita, S. Matsuda and K. Yamamoto: Weld. Res. Suppl., (Oct. 1987), 301
6) Y. Watanabe, M. Katakami, T. Enami, Y. Sumitomo, S. Takashima and K. Yasuda: Soc. Naval Architects Japan, No. 649, (1983), 374

7) Steel Study Group: Japan Welding Soc., 58 (1989), 491

8) H. Mabuchi: 159 th and 160th Nishiyama Memorial Seminar, ISIJ, Tokyo, (1996), 71.

9) K. Okamoto, A. Yoshic, and H. Nakao: Proc. Int. Conf. on Physical Metallurgy of Direct Quenched Steels, Chicago, U.S.A., (Nov. 1992), 339

10) H. Mabuchi, T. Ishikawa and Y. Nomiyama: Proc. Int. Symp. on Accelerated Cooling and Direct Quenching of Steels (Materials Solution, ASM), Indianapolis, U.S.A., (Sept. 1997), 43.

11) D. M. Fegredo: Met. Technol., 4 (1997), 417.

12) C. A. Abel, G. A. Brown, T. Holmes, M. Barenie and J. J. O'Brien: Proc. Conf. on 39th Mechanical Working and Steel Processing, ISS, Indianapolis, U.S.A., 35, (Oct. 1997), 545.

13) A. Yoshie, H. Mabuchi and Y. Onoe: CAMP-ISIJ, 7 (1994), 1840.

14) Y. Nomiyama, T. Ishikawa, T. Hasegawa and T. Haze: CAMP-ISIJ, 7 (1994), 1834

15) N. Ogura: Soc. Naval Architects Japan, 110 (1961), 443.

16) T. Ishikawa, Y. Nomiyama and H. Takezawa: CAMP-ISIJ, 7 (1994), 1772.

17) Y. Nomiyama, T. Hasegawa, T. Ishikawa and H. Yoshikawa: CAMP-ISIJ, 8 (1995), 691

18) T. Hasegawa, Y. Nomiyama and T. Ishikawa: CAMP-ISIJ, 8 (1995), 692

19) T. Ishikawa, Y. Nomiyama, T. Hasegawa, $Y$. Hagiwara and $T$. Inoue: CAMP-ISIJ, 8 (1995), 693

20) T. Ishikawa, Y. Nomiyama, Y. Hagiwara, H. Yoshikawa, S. Oshita and H. Mabuchi: Proc. 14th Int. Conf. on Offshore Mechanics and Arctic Engineering (OMAE 1995), Copenhagen, Denmark, 3, Materials Engineering, ASME, (1995), 357.

21) T. Ishikawa and H. Mabuchi: CAMP-ISIJ, 10 (1997), 1168.

22) T. Ishikawa, Y. Hagiwara, H. Yoshikawa, Y. Nomiyama and H. Mabuchi: Q. J. Jap. Weld. Soc., 15 (1997), 148.

23) H. Yajima, M. Yamamoto, T. Ishikawa and T. Fukui: The West-Japan Soc. Naval Architects, No. 94, (Aug. 1997), 183.

24) M. Yamada, K. Tsukada, Y. Kohsaka, M. Suzuki, S. Shimada and N. Takigawa: NKK Tech. Report, 101 (1984), 10.

25) N. Nozaki, K. Bessyo, H. Ozawa and Y. Kawaguchi: Sumitomo Kinzoku Tech. Report, 37 (1985), 47

26) R. Kinaka, T. Okumura, H. Terashima, S. Minagawa, $Y$. Nakano and S. Matsumoto: Kawasaki Seitetsu Tech. Report, 18 (1986), 321.

27) K. Amano, M. Kimura and S. Ueda: CAMP-ISIJ, 3 (1990), 1796.

28) T. Hayashi, O. Umezawa, S. Torizuka, K. Tsuzaki and K. Nagai: CAMP-ISIJ, 11 (1998), 566.

29) K. Tajimoto, Y. Saiga and M. Hukagawa: Tetsu-to-Hagané, 58 (1972), 1791.

30) S. Kinoshita, T. Ueda and A. Suzuki: Tetsu-to-Hagané, 59 (1973), 446.

31) H. Nakao, R. Yamaba, I. Aoki, T. Kawai, H. Mabuchi and S. Takaishi: Tetsu-to-Hagané, 62 (1976), 1708

32) P. G. Shewmon: Transformation in Metals, McGraw-Hill, New York, (1969), 287.

33) T. Hasegawa: Proc. Symp. on Present and Future of Hot Deformation and Materials, Tokai Branch of Jpn. Inst. Met. (1997), 21.

34) S. Takagi: CAMP-ISIJ, 10 (1997), 1168 